\title{
Pooling Supply Chain: Literature Review of Collaborative Strategies
}

\author{
Abdelhamid Moutaoukil $^{1}$, Ridha Derrouiche ${ }^{2}$, and Gilles Neubert ${ }^{2}$ \\ ${ }^{1}$ Institut Fayol, EMSE, 158 Cours Fauriel, Saint-Etienne, \\ 42000 Saint-Etienne, France \\ ${ }^{2}$ Institut Fayol, ESC Saint-Etienne 51-53 Cours Fauriel BP29 - 42000 \\ Saint-Etienne, France
}

\begin{abstract}
To support companies in collaborative supply chain, new strategies have been set up and developed in the past years. In this context, the first aspect of this paper is to provide an overview of these different collaborative strategies either in vertical or horizontal level. We further develop literature-based constructs for both types of collaboration. After this large-scale survey this paper proposes a conceptual framework for pooling supply chain as an horizontal collaborative logistic strategy. Moreover, our objective is to highlight the link between horizontal collaborative logistic and sustainable development, to show that the strategy of pooling supply chain can achieve the goals of sustainable development, namely, the environmental, economic and societal objectives.
\end{abstract}

Keywords: Pooling Supply Chain, Horizontal collaborative logistic systems, Sustainable development.

\section{Introduction}

In recent years, globalization has made customers increasingly demanding in terms of rate of service, responsiveness and flexibility. The market has become more dynamic and continuously changing. Competitive pressure causes rapid technological advances and introduction of products with shorter life cycles. Consequently, relations between the companies are based more than ever on competitiveness [1]. The current economic context characterized by the financial crisis and declining purchasing power are forcing companies to reorganize their processes and rethink their organizations, to enable them to respond quickly and cost effectively to fast and changing demands.

On the other hand, logistics has gained much attention by significantly increasing the efficiency and flexibility of organizations. The current logistics schemes favor the emergence of new forms of governance and rationalization of logistics systems. Companies now seek to create synergies with other organizations and begin to create value chains through horizontal and / or vertical collaboration with logistics partners. Increasingly, independent firms work together to reduce their operating costs and increase revenues. In collaborative logistics, parties in the supply chain (SC) aimed at reducing logistics costs through better use of their resources ([2] and [3]). 


\section{Concepts and Definitions: Pooling SC}

The literature shows that the efficiency of logistics systems is still inadequate and there is a large potential for improvement in this sector. The inconclusive results of traditional logistics schemes explain the need to develop other strategies to create new logistics systems, more efficient such as the collaborative logistics [4].

Collaborative strategies concern mainly concerted actions between different actors. Competitive advantage is created on the basis of a consensus reached through collaborative relationships. According to Audy and al., collaboration occurs when at least two structures decide to exchange and share physical and/or information resources to make decisions or achieve activities to generate profit [5]. Depending on the degree of commitment and involvement of partners, the collaboration can range from simple information sharing to a true partnership, which may include cultural and organizational changes. Inter-firm collaboration includes other concepts such as cooperation, coordination or co-decision [6].

\subsection{Different Types of Collaborative Logistics}

The literature contains much work on collaborative logistics. For a good overview, see the literature review done by Nagati and al. [7], about collaborative concepts in supply chains.

Nevertheless, the logistical collaboration today takes place primarily at vertical level. Cruijssen reports that supply chain management is the term usually describing vertical collaboration [4], a topic that has led to an abundant scientific literature. Simchi-Levi and al. define management of supply chain as "all of the approaches used to efficiently integrate suppliers, manufacturers, warehouses and stores in way that merchandise is produced and distributed in the right quantities, to right places at the right time, in order to minimize system wide costs while satisfying service level requirements" [8]. This definition indicates that vertical collaboration occurs between partners that operate at different levels of supply network, where the benefits of collaboration include lower supply cost due to synchronization effect by sharing information. Among the main practices of vertical collaboration, we mention: VMI (Vendor Managed Inventory), ECR (Efficient Consumer Response), CPFR (Collaborative Planning Forecasting Replenishment), and CTM (Collaborative Transportation Management).

However, collaboration can also be horizontal [9]. Horizontal collaboration in logistics consists of having collaboration between actors of the same level (between providers, between manufacturers, between distributors, etc) in a supply network. A supply network is considered as non-serial structure and therefore a structure consisting of vertical and horizontal collaboration [2] (Fig. 1). The important benefits of Horizontal collaboration in logistics are: lower prices due to aggregated purchasing quantities, reduced supply risk, reduction of administration cost due to centralized purchasing activities, reduction of inventory and transportation costs, logistics facilities through a rationalization of equipment and better sharing of manpower and information [10]. 


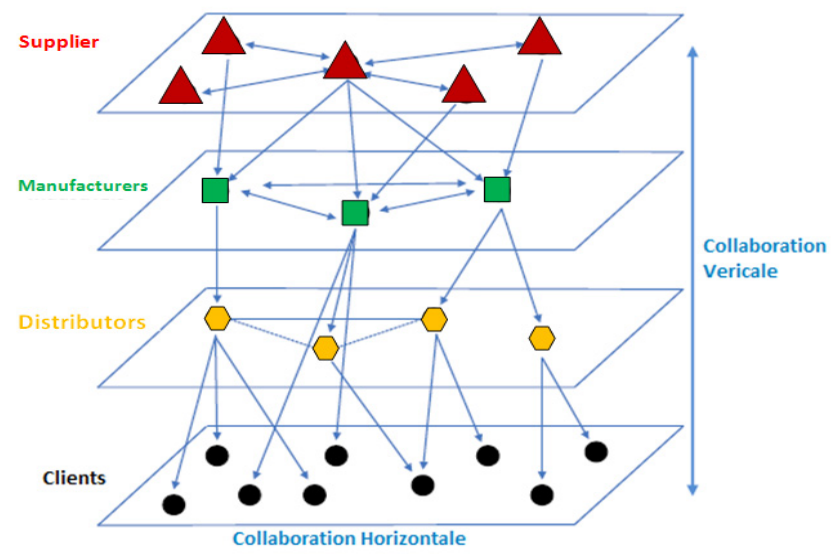

Fig. 1. Types of collaborative logistics

In general, horizontal collaboration in logistics concerns companies that can provide complementary goods or services, competing or not. According to European Commission [11], collaboration is described as "horizontal" if it is the subject of an agreement between companies that are at the same level in the market. It often refers to collaboration between competitors.

Some practices of horizontal collaboration in logistics are: the implantation of the Collaborative Consolidation Centers (CCC), Pooled Procurement Management (PPM), and Collaborative Transportation Management (CTM). We note that the latter practice is common between vertical and horizontal collaboration in logistics, because it involves collaboration in transport that is essential for both types of collaboration.

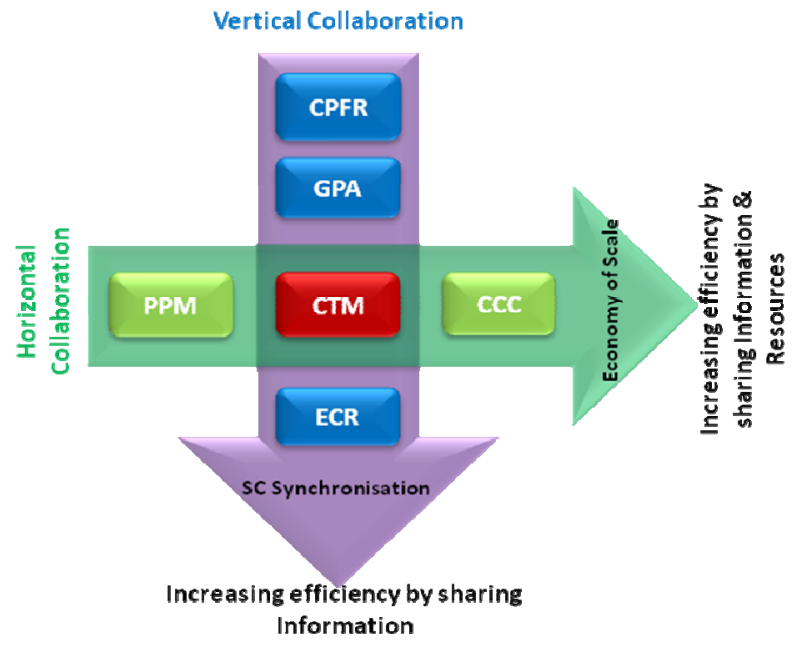

Fig. 2. Practices of collaborative supply network 
In the literature, significant work was done by Cruijssen and Derrouiche in order to identify previous work on this topic ([4] and [12]). For its part, the "Interministerial Pole of Prospective and Anticipating Economic Change" has recently led a study on the various projects in the context of horizontal collaboration in logistics [3]. The study was designed to increase knowledge of new collaborative practices among professional actors in the logistics field. This study has identified challenges and opportunities for collaboration through concrete examples of collaborative supply, and suggested ways accompanied by a summary of good practices observed.

\subsection{Definition of Pooling SC}

Through collaboration, logistics companies in a partnership aim to increase productivity and competitiveness of their logistics networks, by optimizing the use of their means of transport and reducing costs of support activities. In practice, pooling supply chain proved to be an especially useful option for manufacturers and logistics service providers to achieve these objectives and improve their efficiency and competitiveness.

To understand the concept of pooling SC, we refer to the work of Pan [13]. He focuses on the pooled logistics schemes and, more specifically, their impact on $\mathrm{CO} 2$ emissions in the supply chains of mass distribution sector. Pan says that the pooling SC, is the codesign, by actors with a common objective, of a logistics network where resources are pooled (warehouses, platforms, transport, etc..) to share logistical structures, and making available data needed for management to a third party. They add that pooled supply chain effectiveness can meet the concerns of sustainable development.

On the basis of different definitions from the literature such as [13] and [14], we made a detailed definition of pooling supply chain:

"Pooling supply chain is pooling logistics services between several entities to optimize the use and operation of the logistics function or to access a service unavailable individually (example: Multimodal Transport). This requires co-design a common global supply chain. This co-design gives rise to a shared network logistics where different entities share and jointly manage their skills (logistics service manpower, materials handling manpower ...), their structures (distribution warehouses, offices ...) and their means (handling equipment, transport vehicles and fleets, information systems ...)"

The pooling supply chain is a strategy that is not expensive to establish and can, when managed appropriately, help LSP and manufacturers to solve and overcome their chains logistics problems and increase efficiency of their logistics systems [4].

Therefore, the pooling objective consists in integrating partners with the aim of codesigning a logistics network. Such a pooled network allows actors to overcome the constraints of conventional logistics schemes (vertical collaboration). This strategy allows the development of synergies with partners competitor or not, in order to improve economic, environmental and societal performance.

\subsection{Pooling SC and Sustainable Development}

To compete, manufacturers must optimize their Supply Chain (SC). This chain has several links, from the supply of basic raw materials to end use of the product, and even 
beyond to also include its recovery and treatment. But this optimization, long based on an economic approach, happen today through the integration of environmental and social concerns, in line with the objectives of sustainable development. Societal and environmental degradation that go together with economic development calls for serious action from all stakeholders, including regulators such as government, business operators and consumers. Indeed, a constant pressure of European regulations pushes manufacturers to integrate sustainability concerns into their supply chains.

In addition to the requirements of economic efficiency, logistics systems must meet the requirements of sustainable development, namely:

- At the economic level: Reduce logistics costs.

- At the ecological level: Decrease both CO2 emissions and energy consumption, with an incentive to proceed with more recycling and waste treatment [15].

- At the societal level: Consider the expectations of different stakeholders in decisionmaking process of companies [16].

These requirements are more difficult for SMEs to achieve rather than others, because their logistics performance level does not allow them to engage in a sustainable approach ([17] and [18]). In parallel, a just in time logistics policy has been set up in most sectors: deliver faster, more frequently, in smaller quantities. This evolution in flow management explodes SMEs logistics costs, which endangers the entire implementation of sustainable development. In this context of accelerating flow and inventory reduction, pooling supply chain between retailers, manufacturers and logistics providers is more than ever in the core of priorities.

Indeed, it is widely expected that the increased economies of scale are required to mitigate the rise in transportation costs and increased congestion and $\mathrm{CO} 2$ emissions. Hence the importance of a pooling SC strategy between logistics systems, because such a strategy allows them to improve their logistics performance, to monitor the evolution of logistics schemes and initiate sustainable approaches.

\section{$3 \quad$ Literature Review: Pooling SC}

Relevant literature on pooling logistics remains relatively rare. The most relevant scientific works deal with the horizontal collaboration logistics practice. (Table 1) shows a short overview of the literature review we have made.

\subsection{Related Concepts}

Consolidation of flows, horizontal collaboration in logistics and urban mutualization remains the most related concepts to the notion of pooling SC.

Indeed, urban or rural logistics remains an area related to the pooling supply chain as a form of horizontal collaboration in logistics. In this context, Hageback and Segerstedt study the gains and interest of the principle of "codistribution" for rural areas in Pajala in Northern Sweden, where only a third of residents live in the city center while the rest of the population is dispersed over the countryside, making the 
higher costs of delivery to sparsely populated areas, because the delivery distance is longer in these areas and empty runs are more important [19]. Based on a collaborative distribution strategy, co-distribution would ensure the competitiveness of suppliers who are located in rural areas, increase service quality, reduce distribution costs, which would also a positive impact on the environment.

Regarding to distribution networks, Groothedde and al. talk about the concept of "collaborative hub" for many shippers to consolidate flows [20]. The goal is that once the flow massified, can reach sizes needed to be transported by modes of transport at high volume (rail or waterway). Access to this kind of transport can realize economic and ecological benefits.

On the other hand, Cruijssen and al. study the potential benefits and impediments for horizontal collaboration between LSPs in Flanders, Belgium [21]. Possible savings are estimated and the problems of launching co-distribution are stated.

Kale and al. study the collaborative transportation networks where only shippers collaborate; only carriers collaborate and both shippers and carriers collaborate [22]. The authors analyze the benefit of such networks for shippers.

Yilmaz and al. study the coalition formation between shippers of small sizes in a transport market characterized by uncertain demand [23]. They analyze the decisions taken by the coalition and the effect of shippers characteristics on the benefits of collaboration. The analysis shows that shippers continue to benefit from the coalition, but concerning the distribution of costs and gains, the coalition cannot always guarantee a balanced budget that is elementary for the sustainability of any coalition. Using an approach based on game theory, they offer mechanisms for allocating gains and discuss the conditions that carry a balanced budget.

\subsection{Characteristics of Pooling SC Strategy}

As mentioned above, the literature on pooling logistics is rare. However, the theoretical support of its characteristics can be found in the literature of horizontal collaboration in logistics. Moreover, we found through the literature review that there is some similarity between the notion of horizontal collaboration in logistics and pooling supply chain strategy. For that, we relied on works such as [3], [4] and [24], which identified various characteristics of horizontal collaboration logistics.

\section{a) Benefits, disadvantages and impediments of pooling SC}

Benefits that can lead partners to engage in a pooling supply chain strategy can be divided into three groups: Costs and Productivity, Customer Service and Position in the market (Table 2). However, such an initiative may be subject to a number of disadvantages, such as (a) loss of flexibility, as the products purchased must have a strong similarity between the group members, (b) loss of control by individual supply chain, (c) high coordination costs (d) anti-trust problems.

Moreover, the success of this initiative depends on the quality of leadership in the group, since the ability to negotiate contracts and coordinate the interests of its 


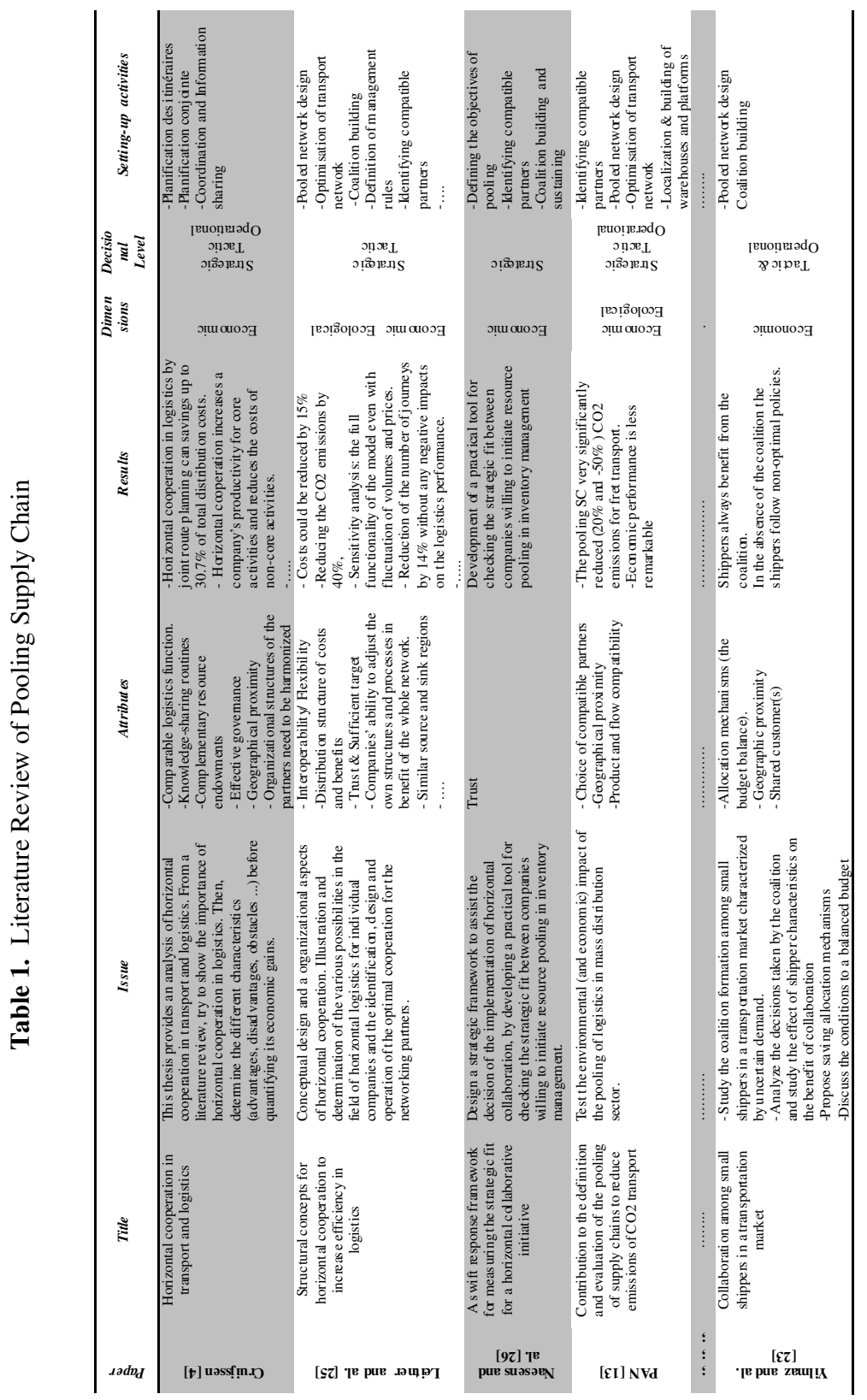


Table 2. Benefits and Impediments of pooling supply chain ([3] and [4])

\begin{tabular}{|c|c|c|c|}
\hline \multicolumn{2}{|r|}{ Pooling SC Advantages } & \multicolumn{2}{|c|}{ Pooling SC Impediments } \\
\hline \multirow{3}{*}{$\begin{array}{l}\text { Costs and } \\
\text { productivity }\end{array}$} & Cost reduction & \multirow{5}{*}{ Partners } & $\begin{array}{c}\text { Difference in interests, opportunistic } \\
\text { behavior }\end{array}$ \\
\hline & $\begin{array}{l}\text { Learning and internalisation of tacit, } \\
\text { collective and embedded knowledge and } \\
\text { skills }\end{array}$ & & Difficulty in finding fit partners \\
\hline & $\begin{array}{l}\text { More skilled (or more efficient use of) } \\
\text { manpower }\end{array}$ & & \begin{tabular}{|c|} 
Difficulty in finding a trusted \\
party/person to lead the cooperation
\end{tabular} \\
\hline \multirow{3}{*}{ Customer service } & Complementary goods and services & & \\
\hline & $\begin{array}{l}\text { Ability to comply to strict customer } \\
\text { requirements / Improved service }\end{array}$ & & Differences in operating procedures \\
\hline & Specialisation & \multirow{4}{*}{$\begin{array}{l}\text { Determining and } \\
\text { dividing the gains }\end{array}$} & Difficulty in determining the benefits \\
\hline \multirow{5}{*}{ Market position } & Penetrating new markets & & \\
\hline & New product development/R\&D & & Difficulty in establishing a fair \\
\hline & Serving larger customers & & allocation of the benefits \\
\hline & Protecting market share & \multirow[t]{3}{*}{ Negotiation } & $\begin{array}{l}\text { Disagreement over the domain of } \\
\text { decisions }\end{array}$ \\
\hline & Faster speed to market & & Unequal bargaining positions (e.g. \\
\hline \multirow{4}{*}{ Other } & Developing technical standards & & due to size differences) \\
\hline & Accessing superior technology & \multirow{3}{*}{$\begin{array}{c}\text { Coordination and } \\
\text { ICT (Information } \\
\text { \&Communication } \\
\text { Technology) }\end{array}$} & High indispensable ICT costs \\
\hline & Overcoming legal/regulatory barriers & & $\begin{array}{l}\text { High additional coordinating and } \\
\text { controlling costs }\end{array}$ \\
\hline & Enhancing public image & & Loss of control \\
\hline
\end{tabular}

members is essential [10]. In addition, several barriers may hinder a strategy of pooling supply chain (table 2 ).

\section{b) Pooling SC attributes}

Pecqueur and Zimmermann introduced the concept of "dynamic proximity" as the global attribute that query the terms of the coordination of economic and social activities by integrating their explicit spatial dimension [27]. The notion of proximity can be understood as:

- Geographical proximity, which refers to the separation of actors in space;

- Organizational proximity, concerning economic interactions between actors with complementary resources and participants completed the same activity;

- Institutional proximity, which relies on the support of players in a common system of representations.

- Product Proximity, which refers to the compatibility between products and between pooled physical flows.

Through the literature review that we conducted (Table 1), we have compiled the most important attributes that are required for a successful pooling supply chain strategy:

- Transparency and Trust

- Strategic fit: Common interest and commitment and clear expectations 
- Choice of sustainable and compatible partners which have comparable logistics function: flows and product compatibility, Shared customer(s)

- Leadership and coordination.

- Geographic proximity

- Interoperability / Flexibility: Companies' ability to adjust the own structures and processes in benefit of the whole network

\section{Towards a Framework for Implementing Pooling SC Strategy}

Literature lacks a general conceptual framework to guide practitioners in implementing pooling supply chain strategy. From literature review, we provide a framework for implementing pooling supply chain strategy.

The establishment of logistics strategies involves sharing and pooling different activities on different decision levels of the company. Naesens and al. give a practical tool for checking the strategic fit between companies willing to initiate resource pooling in inventory management [26]. Activities at the operational level focus on daily operations within companies or logistics departments. They are practical operations and can be described as "joint execution" or the "sharing of operational information." Activities at the tactical level refer to achieving medium term objectives and involve more intensive planning and investment. They formalize "the common organization", or "sharing of logistics resources." Activities at strategic level aimed at achieving the strategic objectives of the coalition in the long term. Strategic collaboration at this level can be described as the "co-development".

Blanquart states that any collaboration passes through a life cycle that involves four steps: the engagement process, the management of interdependencies, the effective implementation of operations, and the evaluation process [28].

From literature review (Table 2), we have selected and compiled the various activities necessary to implementing a pooling supply chain strategy. We mention these various activities in (Fig. 3.). We develop some of these activities:

- Pooled network design: the definition of an optimal logistic concept is the main requirement to create synergies between partners. Therefore, the definition and the design of new structures and processes form the basis of a successful pooling supply chain strategy.

- The location and building of warehouses are of great importance for the efficiency of transport processes. By means of warehouse sharing, manufacturers can reduce their warehousing costs (investments, handling, conditioning, etc.).

- Optimization of transport network: the aim of increasing efficiency within a pooling supply chain can be achieved by means of reducing waste within the transportation network. Joint route planning is essential to estimate the potential savings and their sensitivity to various market characteristics. 
- Supply and distribution planning: depending on production planning of each partner and the number of shipments and the complexity caused by various recipients with different delivery restrictions. This planning requires increasing effort for scheduling within the network and needs to invest in infrastructure and personnel.

- Designing an adequate information system and sharing information: coordination and communication are important catalysts of collaboration. In an economy that strongly depends on information flows, obtaining the most accurate and real-time information offers the key to success. To realize this, the organizational structures of the partners need to be harmonized, which also requires far-reaching ICT integration [29]. Besides of transport structures and transport processes, sharing information and coordinating the planning processes are also relevant for the design of pooling supply chain concept.

- Establishment of an organizational structure: both the design and operations of the network require a coordinator that ensures the overall partners satisfaction and improvement of the logistics network. This organizational structure acts as a managing and coordinating entity, it must ensure [25]:

$\checkmark$ Neutrality in handling or priority of jobs

$\checkmark$ Confidentiality regarding the given data

$\checkmark$ Joint definition of rules and regulations and processes

$\checkmark$ Definition and implementation of interfaces (IT requirements)

$\checkmark$ Availability of contact person or local contact point

$\checkmark$ Planning, executing and controlling the logistic performance for partners

$\checkmark \quad$ Fair cost-benefit distribution

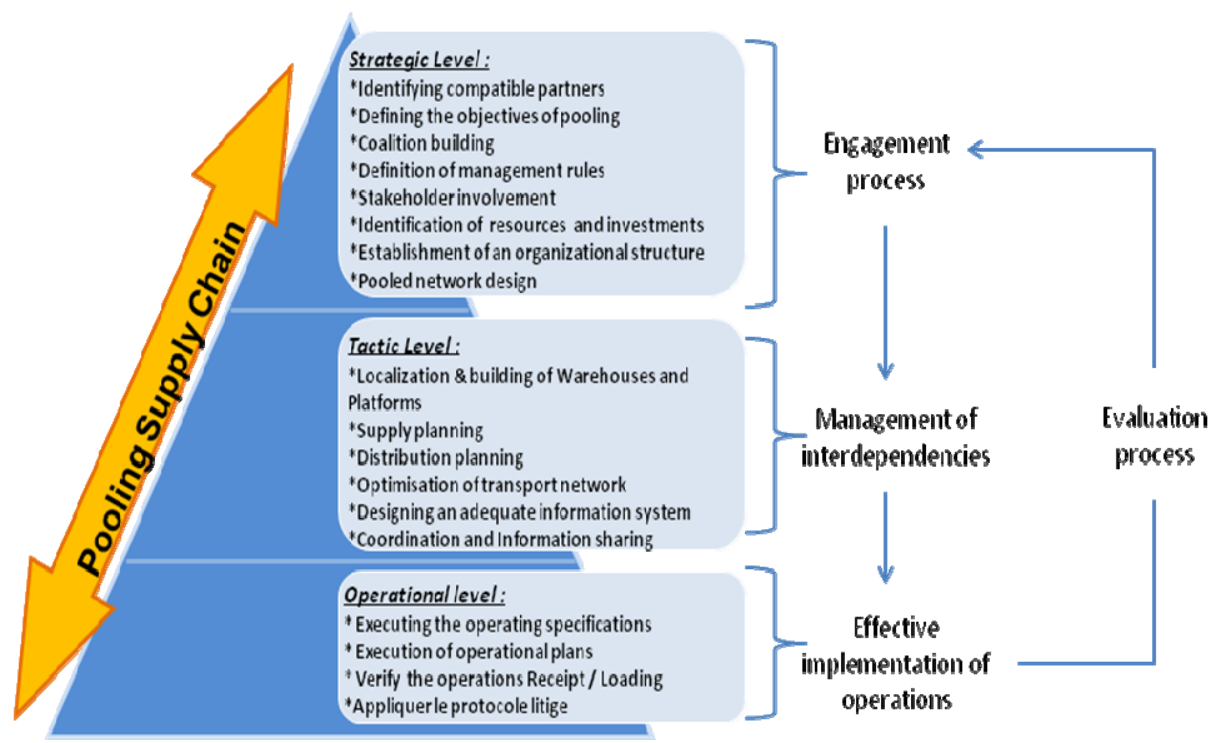

Fig. 3. Framework of implementation the pooling supply chain 


\section{Conclusion}

Business networking strategies and especially collaboration in logistics are gaining momentum for individual companies in order to survive in competitive markets. As pooling supply chain is a new and powerful strategy to maximize benefits structures, this publication present an overview of collaborative logistics. A literature survey indicates that the pooling supply chain is a new concept which requires a deep scientific research to assimilate its various aspects. Special attention is further dedicated to understand the principle of horizontal collaboration in logistics as well as the specifications of pooling supply chain strategy, which are both considered as a form of collaborative logistics. Despite persuasive research, a major theoretical and practical shortcoming is the lack of a framework that gathers the activities necessary to implementing pooling supply chain strategy. The identification of this framework is one of the major strengths of this research.

However, this work is merely a starting point for future research on the pooling supply chain design in practice. More research is needed in order to make the given framework exhaustive and robust.

Acknowledgments. Authors would like to thank Region Rhône-Alpes for its financial support (Research Cluster GOSPI).

\section{References}

1. Zigmas, L., Benas, A.: Cooperation among the Competitors in International Cargo Transportation Sector: Key Factors to Success. Engineering Economics 51(1), 80-90 (2007)

2. Mason, R., Lalwani, L., Boughton, R.: Combining vertical and horizontal collaboration for transport optimisation. Supply Chain Management: An International Journal 12(3), 187199 (2007)

3. PIPAME: Pratiques de logistique collaborative: Quelles opportunités pour les PME/ETI? Le pôle interministériel de prospective et d'anticipation des mutations économiques, Paris (2011)

4. Cruijssen, F.: Horizontal cooperation in transport and logistics. PhD thesis. Tilburg, Nederland (2006)

5. Audy, J.-F., Lehoux, N., D’Amours, S., Ronnqvist, M.: A framework for an efficient implementation of logistics collaborations. International Transactions in Operational Research 18 (2011)

6. Camalot, J.-P.: Aide à la décision et à la coopération en gestion du temps et des ressources. $\mathrm{PhD}$ thesis, INSA Toulouse (2000)

7. Nagati, H., Rebolledo, C., Jobin, M.H.: Analyse de la collaboration entre industriels et distributeurs: le cas de la grande distribution française. In: 7èmes rencontres internationales de la recherche en logistique, Avignon, pp. 24-26 (2008)

8. Simchi-Levi, D., Kaminsky, P., Simchi-Levi, E.: Designing and managing the supply chain: Concepts, strategies, and cases. McGraw-Hill (2000) 
9. Van Lier, T., et al.: Internal and external co-loading of outbound flows to increase the sustainability of transport: a case study. In: 12th WCTR, Lisbon-Portugal, July 11-15 (2010)

10. Bahinipati, B.K., Kanda, A., Deshmukh, S.-G.: Horizontal collaboration in semiconductor manufacturing industry supply chain: An evaluation of collaboration intensity index. Computers \& Industrial Engineering, 880-895 (2009)

11. European Union: Guidelines on the applicability of Article 81 of the EC Treaty to horizontal cooperation agreements. Official Journal of the European Communities 2001/C 3/02 (2001)

12. Derrouiche, R.: Analyse et caractérisation des relations dynamiques entre partenaires d'une chaine logistique. PhD thesis. Université Lumière - Lyon II, Frence (2007)

13. Pan, S.: Contribution à la définition et à l'évaluation de la mutualisation de chaînes logistiques pour réduire les émissions de $\mathrm{CO} 2 \mathrm{du}$ transport: application au cas de la grande distribution. PhD thesis. Mines Paris Tech., Paris (2010)

14. Ballot, E., Fontane, F.: Reducing transportation $\mathrm{CO} 2$ emissions through pooling of supply networks: perspectives from a case study in French retail chains. Production Planning \& Control: The Management of Operations 21(6), 640-650 (2010)

15. Ülkü, M.-A.: Dare to care: Shipment consolidation reduces not only costs, but also environmental damage. International Journal of Production Economics (2011)

16. Belin-Munier, C.: Logistique, SCM, et développement durable: Une revue de la littérature. Environmental Management (2009)

17. Conservatoire National des Arts et Métiers (CNAM): Enquête Nationale : La logistique dans les PME-PMI de l'agroalimentaire, synthese des resultats. Chaire de Logistique, Transport, Tourisme (2007)

18. Pôle Agroalimentaire Loire: Organisation logistique du secteur agroalimentaire dans la Loire. Saint-Etienne (2011)

19. Hageback, C., Segerstedt, A.: The need for co-distribution in rural areas-a study of Pajala in Sweden. International Journal of Production Economics 89(2), 153-163 (2004)

20. Groothedde, B., Ruijgrok, C., Tavasszy, L.: Towards collaborative, intermodal hub networks: a case study in the fast moving consumer goods market. Transportation Research Part E: Logistics and Transportation Review 41(6), 567-583 (2005)

21. Cruijssen, F., Cools, M., Dullaert, W.: Horizontal cooperation in logistics: Opportunities and Impediments. Transportation Research Part E: Logistics and Transportation Review 43(2), 129-142 (2007)

22. Kale, R., Evers, P.-T., Dresner, M.-E.: Analyzing private communities on internet- based collaborative transportation networks. Transportation Research Part E 43, 21-38 (2007)

23. Yilmaz, O., Savasaneril, S.: Collaboration among small shippers in a transportation market. European Journal of Operational Research 218(2), 408-415 (2011)

24. Derrouiche, R., Neubert, G., Bouras, A., Savino, M.: B2B Relationship Management: A Framework to Explore Impact of Collaboration. International Journal of Production Planning \& Control (IJPPC) 21(6), 528-546 (2010)

25. Leitner, R., Meizer, F., Prochazka, M., Sihn, W.: Structural concepts for horizontal cooperation to increase efficiency in logistics. CIRP Journal of Manufacturing Science and Technology 4(3), 332-337 (2011)

26. Naesens, K., Gelders, L., Pintelon, L.: A swift response framework for measuring the strategic fit for a horizontal collaborative initiative. International Journal of Production Economics 121(2), 550-561 (2009) 
27. Pecqueur, B., Zimmermann, J.-B.: L'économie de proximités, 264 p. Hermes- Lavoisier, Paris (2004)

28. Blanquart, C., Carbone, V.: Pratiques collaboratives et demarche environnementale dans la supply chain: mythe ou réalité?. In: 8th International Meeting on Logistics Research, BEM-Bordeaux Management School (2010)

29. Gunnarsson, C., Jonsson, S.: Charge the relationship and gain loyalty effects: Turning the supply link alert to IT opportunities. European Journal of Operational Research 144(2), 257-269 (2003) 